\title{
Treatment of moderate-to-high hyperopia with the WaveLight Allegretto 400 and EX500 excimer laser systems
}

This article was published in the following Dove Press journal:

Clinical Ophthalmology

24 May 2017

Number of times this article has been viewed

\author{
Manoj Motwani' \\ Ronald Pei ${ }^{1,2}$ \\ 'Motwani LASIK Institute, San Diego, \\ ${ }^{2}$ Precision Outcome Consultants, \\ Fresno, CA, USA
}

Purpose: To evaluate the efficacy of treating patients with +3.00 diopters (D) to $+6.00 \mathrm{D}$ of hyperopia via laser-assisted in situ keratomileusis (LASIK) with the WaveLight Allegretto 400 and EX500 excimer laser systems.

Setting: Private clinical ophthalmology practice.

Patients and methods: This was a retrospective study of patients undergoing LASIK treatments of +3.00 to $+6.00 \mathrm{D}$ on two different WaveLight laser systems: 163 eyes on the 400 (Hertz) Hz system and 54 eyes on the $500 \mathrm{~Hz}$ system. The duration of follow-up was 6 months postoperation. Data were evaluated for uncorrected distance visual acuity, corrected distance visual acuity (CDVA), spherical equivalents (SEQs), and changes in these parameters (eg, loss of vision, regression over time).

Results: Treatment with both lasers was safe and effective, with loss of one line of CDVA in four of 162 eyes using the $400 \mathrm{~Hz}$ laser system, and none of the 54 eyes with the $500 \mathrm{~Hz}$ laser system. Overall, regression $\geq 0.75 \mathrm{D}$ from goal at 6 months was observed in $11.7 \%(19 / 163)$ of eyes in the $400 \mathrm{~Hz}$ laser group and $9.26 \%(5 / 54)$ of eyes in the $500 \mathrm{~Hz}$ laser group (regression $\geq 0.50 \mathrm{D}=77.9 \%$ [127/163] and 77.8\% [42/54], respectively). The mean SEQ regressions for all eyes with moderate hyperopia were 0.10 and $0.18 \mathrm{D}$ for those with high hyperopia.

Conclusions: Both the 400 and $500 \mathrm{~Hz}$ excimer laser systems were safe and effective for the LASIK treatment of moderate-to-high hyperopia. The overall rate of regression was low and the amount of regression was relatively small with both systems.

Keywords: excimer laser, hyperopia, laser-assisted in situ keratomileusis, LASIK, regression

\section{Introduction}

Although excimer laser ablation has been available for the treatment of hyperopia for well over a decade and a half now, the general perception among refractive surgeons is that the regression rate and amounts are unacceptably high. Due to this, patients who have moderate-to-high amounts of hyperopia often go untreated as refractive surgeons feel that the results will not be acceptable.

The advancement of technology in excimer lasers has changed the stability and regression of hyperopic corrections, resulting in US Food and Drug Administration (FDA) approval of the WaveLight Allegretto 400 and EX500 systems of up to 6.00 diopters (D) of hyperopia/hyperopic astigmatism correction. ${ }^{1-3}$ This was primarily due to a wide optical zone of ablation, rapid ablation times from high repetition rates, and faster, more accurate eye scanners. Essentially, although the technology improved, the recommendation from senior and trusted refractive surgeons was that corrections 
over $+4.00 \mathrm{D}$ of hyperopia should not be performed, and many even recommended only performing procedures under +3.00 D.

What the authors have noted in clinical practice is that performing correction of moderate-to-high hyperopia on the WaveLight Allegretto 400 and EX500 lasers was not only effective, but showed lower rates of regression than earlier studies had displayed. Patients had high amounts of correction, and would show no regression, and excellent stability of their vision.

This retrospective study was undertaken to quantify this clinical experience, and determine the accuracy and effectiveness of treating corrections of a spherical equivalent (SEQ) of +3.00 to $+6.00 \mathrm{D}$ of hyperopia/hyperopic astigmatism. Furthermore, we quantitated the percentage and amount of regression, and also were able to make some comparisons between the outcomes of the two WaveLight lasers.

\section{Patients and methods}

This was a single-center retrospective study using two FDAapproved excimer laser systems (WaveLight Allegretto 400 Hertz (Hz) and EX500-500 Hz; Alcon, Fort Worth, TX, USA) for laser-assisted in situ keratomileusis (LASIK) procedures. All patients were treated unilaterally or bilaterally for on-label indications: moderate (the SEQ of +3.0 to +4.99 D) to high hyperopia (the SEQ of +5.0 to $+6.0 \mathrm{D}$ ). The study was conducted in accordance with Good Clinical Practice Standards and applicable regulatory requirements.

\section{Patients}

This retrospective study was approved by the Salus IRB (Austin, TX, USA). All patients consented in written form to having their data used as part of this study without any identifying personal factors as part of our clinical consent process for LASIK surgery.

Consecutive patients treated with WaveLight Allegretto $400(400 \mathrm{~Hz})$ or EX500 $(500 \mathrm{~Hz})$ excimer laser systems for hyperopia from $03 / 01 / 2014$ to $08 / 31 / 15$ with LASIK were screened for study eligibility and patients who were treated with photorefractive keratectomy (PRK) or surface ablation modalities were not included. The inclusion criteria were $1) \geq 18$ years old at the time of surgery; 2) refractive ranges between +3.0 and $+6.0 \mathrm{D}$ of hyperopia and a cylinder correction range of $\pm 6.0 \mathrm{D}$ preoperatively; and 3 ) with primary outcome data available for both baseline and month 6 follow-up for the study eye. Patients with +3.0 to $+4.99 \mathrm{D}$ of hyperopia were classified as moderate hyperopes, while those with +5.0 to $+6.0 \mathrm{D}$ were classified as high hyperopes.
All patients had corrections that kept them under a final topographic $\mathrm{K}$ value of $50.0 \mathrm{D}$; if a prospective patient had a hyperopic correction that would take the K over 50.0 D, they did not have laser correction performed. All patients in this study either had a goal of full correction (plano), or monovision correction (usually -1.00 to $-1.50 \mathrm{D}$ ), which would increase the amount of hyperopic correction performed.

All patients had cyclopleged refractions performed, and only the cyclopleged refraction was used for treatment to avoid any residual refraction from latent hyperopia.

Patient exclusion criteria were as follows: 1) had undergone multifocal ablations, PRK, or phototherapeutic keratectomy surgeries; 2) suffering from acute or recurring eye diseases; 3 ) history of significant dry eye that was unresponsive to treatment; 4) an ocular disease and/or condition that, in the investigator's clinical judgment, may have compromised study results; 5) any corneal ectasia, history of herpes simplex or herpes zoster keratitis; or 6) severe allergies.

\section{Treatment}

Surgivision Datalink and IBRA surgical planning system was, respectively, used for procedures with the Allegretto 400 and the EX500. Numbing eye drops were given prior to surgery. Ablations were centered on the corneal apex. Either a Moria M2 microkeratome or a Ziemer femtosecond laser was used to create a flap of tissue from the upper layer of the cornea. The flap was folded back to expose the inner layers of the cornea. The excimer laser systems (400 or $500 \mathrm{~Hz}$ ) were then used to shape the cornea using the wavefront-optimized treatment. The flap was replaced once the laser treatment was completed.

\section{Adverse events}

Any surgical complications, immediately postoperation, and postoperation complications denoted in patients' charts were documented. If available, detailed information regarding the adverse events (AEs) such as the type of event, onset day and resolution date, action taken and results, as well as its relationship to surgery or treatment were documented.

\section{Data management and statistical methods}

Case report forms specifically designed per study protocol specification were used for data collection. Chart reviews and data abstraction were conducted by designated trained staff. Deidentified data were stored electronically and processed by an independent biostatistician who did not participate in patient selection or data collection. Statistical analysis 
was performed using SAS-PC 9.4 (SAS Institute, Cary, NC, USA).

Patient demographic and clinical characteristics are described using summary statistics such as mean, standard deviation (SD), and percentage. Each eye served as the analytical unit. Improvement in visual acuity was determined by comparing the month 6 postoperation uncorrected distance visual acuity (UDVA) to the baseline corrected distance visual acuity (CDVA) expressed as ETDRS letters. Regression at the 6-month follow-up in visual acuity was the primary efficacy parameter for this study. The secondary endpoint was the improvement in manifest refraction at 6 months post-treatment compared to refraction readings taken before treatment. These are expressed as Snellen visual acuities.

Each eye was considered to be an analytical unit. Between-group comparisons were conducted using the Student's $t$-test for numeric variables and Pearson's chisquare test for categorical variables. All tests were two-sided with the confidence level set to $95 \%$.

\section{Results}

There were 163 eyes from 114 patients in the Allegretto 400 series, and 54 eyes from 38 patients in the EX500 series.
Most of the patients $(57.89 \% ; 88 / 152)$ were females. The overall average patient age was $51.27( \pm 11.99 \mathrm{SD})$ years. Sixty-six patients $(43.42 \%)$ underwent bilateral surgery and $86(56.58 \%)$ unilateral. Patients with bilateral surgery accounted for $43.86 \%$ (50 patients) of the Allegretto 400 series and $42.11 \%$ (16 patients) in the EX500 series.

Preoperatively, most patients had moderate hyperopia (77.91\% in the Allegretto 400 series and $61.11 \%$ in the EX500 series) (Table 1). The average baseline SEQs were 4.29 for the Allegretto 400 series and 4.26 for the EX500 series. Prior to surgery the UDVA averaged 111.45 and 115.30 in the two groups, respectively. The baseline hyperopia and cylinder values were significantly different between the two treatment series ( $P=0.0150$ and $P=0.0025)$.

Using a target of near vision, the average SEQs were 4.22 for the Allegretto 400 series and 3.95 for the EX500 series (Table 2). Prior to surgery the UDVA averaged 94.35 and 90.43 , respectively. The baseline cylinder values were significantly different between the two series $(P=0.0253)$.

Using a target of distance vision, the average SEQs were $+4.30 \mathrm{D}$ for the Allegretto 400 series and $+4.75 \mathrm{D}$ for the EX500 series (Table 3). Prior to surgery the UDVA averaged 142.5 and 106.6, respectively. Baseline values

Table I Baseline clinical assessments

\begin{tabular}{|c|c|c|c|c|}
\hline Variables & $\begin{array}{l}\text { Total } \\
(\mathrm{N}=2 \mid 7)\end{array}$ & $\begin{array}{l}\text { Allegretto } 400 \\
(n=163)\end{array}$ & $\begin{array}{l}\text { EX500 } \\
(n=54)\end{array}$ & $P$-value ${ }^{a}$ \\
\hline Surgical eye, n (\%) & & & & 0.5930 \\
\hline Left & 134 (6I.75\%) & 99 (60.74\%) & $35(64.81 \%)$ & \\
\hline Right & $83(38.25 \%)$ & $64(39.26 \%)$ & $19(35.19 \%)$ & \\
\hline Hyperopia, n (\%) & & & & 0.0150 \\
\hline Moderate $(3-4 \mathrm{D})$ & 160 (73.73\%) & I27 (77.91\%) & $33(61.11 \%)$ & \\
\hline High (5-6 D) & $57(26.27 \%)$ & $36(22.09 \%)$ & $21(38.89 \%)$ & \\
\hline Sphere (D) & & & & 0.1241 \\
\hline Mean \pm SD & $4.65 \pm 1.00$ & $4.58 \pm 0.89$ & $4.87 \pm I .27$ & \\
\hline Range & $3.00-08.25$ & $3.00-06.75$ & $3.00-08.25$ & \\
\hline Cylinder ${ }^{\mathrm{b}}$ (D) & & & & 0.0025 \\
\hline Mean \pm SD & $-0.75(0.86)$ & $-0.64 \pm 0.79$ & $-1.17 \pm 1.01$ & \\
\hline Range & -4.50 to 0 & -4.50 to 0.00 & -4.50 to 0.00 & \\
\hline SEQ (D) & & & & 0.3196 \\
\hline Mean \pm SD & $4.29(0.87)$ & $4.26 \pm 0.81$ & $4.4 I \pm I .03$ & \\
\hline Range & $3.00-07.25$ & $3.00-06.00$ & $3.00-07.25$ & \\
\hline UDVA & & & & 0.3722 \\
\hline Mean \pm SD & 111.45 (I53.25) & $115.30 \pm 170.30$ & $99.72 \pm 82.7 \mid$ & \\
\hline Range & $20-2,000$ & $20-2,000$ & $25-400$ & \\
\hline CDVA $^{c}$ & & & & 0.2853 \\
\hline Mean \pm SD & $21.91(9.61)$ & $21.24 \pm 3.99$ & $23.89 \pm 17.87$ & \\
\hline Range & $20-150$ & $20-50$ & $20-150$ & \\
\hline Goal & & & & 0.0461 \\
\hline Mean \pm SD & $-0.79(0.75)$ & $-0.85 \pm 0.75$ & $-0.62 \pm 0.73$ & \\
\hline Range & -2.25 to 0 & -2.25 to 0.00 & -1.75 to 0 & \\
\hline
\end{tabular}

Notes: a ${ }^{P}$-values of chi-square test for categorical variables and of Student's $t$-test for numeric variables for comparison between Allegretto 400 and EX500. ${ }^{b}$ Data not available for 12 eyes in the EX500 group. 'Data not available for two eyes in the Allegretto 400 group. For UDVA and CDVA, values presented are Snellen denominators. Abbreviations: CDVA, corrected distance visual acuity; D, diopters; SD, standard deviation; SEQ, spherical equivalent; UDVA, uncorrected distance visual acuity. 
Table 2 Baseline assessments - targeted vision $=$ near

\begin{tabular}{|c|c|c|c|}
\hline Variables & $\begin{array}{l}\text { Allegretto } 400 \\
\text { ( } \mathrm{N}=92 \text { eyes) }\end{array}$ & $\begin{array}{l}\text { EX500 } \\
(\mathrm{N}=23 \text { eyes })\end{array}$ & $P$-value ${ }^{a}$ \\
\hline Surgical eye, n (\%) & & & 0.1868 \\
\hline Right & $24(26.09 \%)$ & 3 (13.04\%) & \\
\hline Left & $68(73.91 \%)$ & $20(86.96 \%)$ & \\
\hline Sphere (D) & & & 0.2374 \\
\hline Mean \pm SD & $4.43 \pm 0.77$ & $4.22 \pm 0.83$ & \\
\hline Range & $3.00-6.00$ & $3.00-6.00$ & \\
\hline Cylinder ${ }^{\mathrm{b}}$ (D) & & & 0.0253 \\
\hline Mean \pm SD & $-0.42 \pm 0.53$ & $-0.77 \pm 0.7 \mid$ & \\
\hline Range & -2.50 to 0.00 & -3.00 to 0.00 & \\
\hline SEQ (D) & & & 0.1301 \\
\hline Mean \pm SD & $4.22 \pm 0.76$ & $3.95 \pm 0.77$ & \\
\hline Range & $3.00-6.00$ & $3.00-5.50$ & \\
\hline UNVA & & & 0.7790 \\
\hline Mean \pm SD & $94.35 \pm 83.94$ & $90.43 \pm 51.65$ & \\
\hline Range & $20-400$ & $30-200$ & \\
\hline CNVA $^{c}$ & & & 0.0765 \\
\hline Mean \pm SD & $20.44 \pm 1.62$ & $22.39 \pm 4.97$ & \\
\hline Range & $20-30$ & $20-40$ & \\
\hline Goal & & & 0.4444 \\
\hline Mean \pm SD & $-1.47 \pm 0.22$ & $-1.45 \pm 0.13$ & \\
\hline Range & -2.25 to 0.00 & -1.75 to -1.25 & \\
\hline
\end{tabular}

Notes: ${ }^{2}$-values of chi-square test for categorical variables and of Student's $t$-test for numeric variables. ${ }^{b}$ Data available for 16 eyes in the EX500 group. ${ }^{~}$ Data available for 90 eyes in the Allegretto 400 group. For UDVA and CVDA, values presented are Snellen denominators.

Abbreviations: CNVA, corrected near visual acuity; D, diopters; SD, standard deviation; SEQ, spherical equivalent; UNVA, uncorrected near visual acuity.

Table 3 Baseline assessments - targeted vision = distance

\begin{tabular}{|c|c|c|c|}
\hline Variables & $\begin{array}{l}\text { Allegretto } 400 \\
(\mathrm{~N}=7 \mid \text { eyes })\end{array}$ & $\begin{array}{l}\text { EX500 } \\
(\mathrm{N}=31 \text { eyes })\end{array}$ & $P$-value ${ }^{a}$ \\
\hline Surgical eye, n (\%) & & & 0.6591 \\
\hline Right & 40 (56.34\%) & $16(51.61 \%)$ & \\
\hline Left & 31 (43.66\%) & I5 (48.39\%) & \\
\hline Sphere (D) & & & 0.0330 \\
\hline Mean \pm SD & $4.76 \pm 0.99$ & $5.35 \pm 1.34$ & \\
\hline Range & $3.00-6.75$ & $3.25-8.25$ & \\
\hline Cylinder (D) & & & 0.0311 \\
\hline Mean \pm SD & $-0.92 \pm 0.97$ & $-1.42 \pm 1.10$ & \\
\hline Range & -4.5 to 0.00 & -4.50 to 0.00 & \\
\hline SEQ (D) & & & 0.0267 \\
\hline Mean $\pm S D$ & $4.30 \pm 0.86$ & $4.75 \pm 1.08$ & \\
\hline Range & $3.00-6.00$ & $3-7.25$ & \\
\hline UDVA & & & 0.2859 \\
\hline Mean \pm SD & $142.5 \pm 238.0$ & $106.6 \pm 100.1$ & \\
\hline Range & $25-2,000$ & $25-400$ & \\
\hline CDVA & & & 0.5217 \\
\hline Mean \pm SD & $22.25 \pm 5.59$ & $25.00 \pm 23.31$ & \\
\hline Range & $20-50$ & $20-150$ & \\
\hline Goal & & & 0.1588 \\
\hline Mean \pm SD & $-0.04 \pm 0.25$ & $0.00 \pm 0.00$ & \\
\hline Range & -1.50 to 0.00 & 0.00 to 0.00 & \\
\hline
\end{tabular}

Notes: ${ }^{a}$-values of chi-square test for categorical variables and of Student's $t$-test for numeric variables. 'Data available for 26 eyes in the EX500 group. For CDVA and UDVA, values presented are Snellen denominators.

Abbreviations: CDVA, corrected distance visual acuity; D, diopters; SD, standard deviation; SEQ, spherical equivalent; UDVA, uncorrected distance visual acuity.

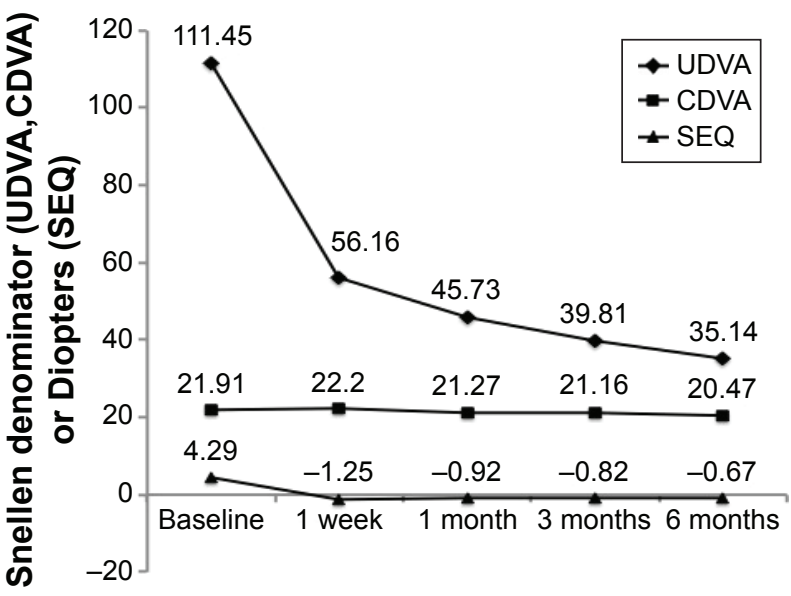

Figure I Visual acuity and SEQ evaluations from baseline to 6 months.

Notes: UDVA and CDVA are shown as Snellen denominators. SEQ is measured in diopters.

Abbreviations: CDVA, corrected distance visual acuity; SEQ, spherical equivalent; UDVA, uncorrected distance visual acuity.

were significantly different between the two series for sphere ( $P=0.0330)$, cylinder $(P=0.0311)$, and SEQ $(P=0.0267)$.

Clinically significant improvements in UDVA, CDVA, and SEQ were observed after surgery (Figure 1). The average UDVA improved from 111.45 at baseline to 35.14 at 6 months, while the average SEQ improved from $+4.29 \mathrm{D}$ at baseline to $-0.67 \mathrm{D}$ at 6 months.

Overall, no differences were observed at month 6 follow-up between the moderate and high hyperopes in CDVA, as well as the gain or loss of lines of vision. The average CDVAs for the moderate and high hyperopes were similar ( 0.22 and 0.21 , respectively, Figure 2 ). About one in

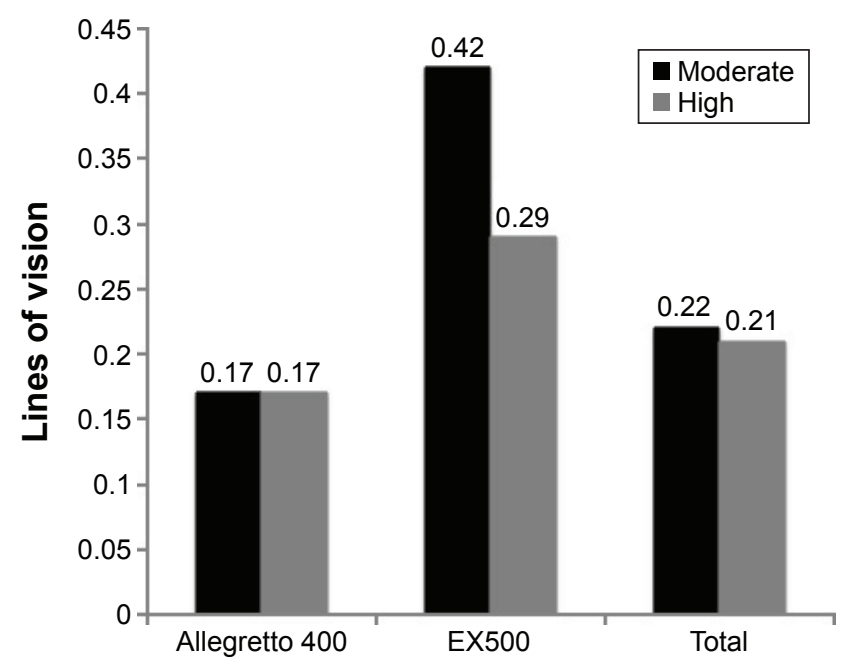

Figure 2 Average CDVA gain/loss of lines measured in ETDRS letters.

Notes: $P$-values of two-sided Student's $t$-test for comparisons between patients with moderate and high hyperopia. High, high hyperopia 5.00-6.00 D; Moderate, moderate hyperopia 3.00-4.99 D.

Abbreviations: CDVA, corrected distance visual acuity; D, diopters; ETDRS, ETDRS letters. 


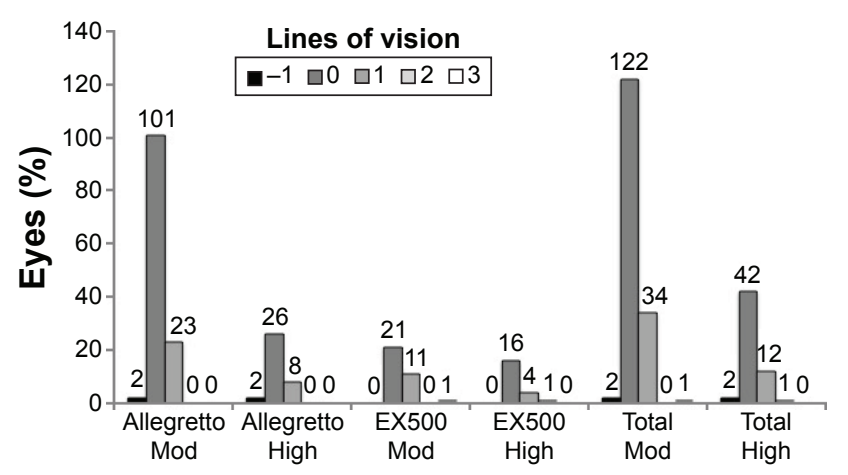

Figure 3 CDVA gain/loss of lines.

Notes: $P$-value of chi-square test for comparisons between patients with moderate and high hyperopia. High, high hyperopia 5.00-6.00 D; Mod, moderate hyperopia 3.00-4.99 D.

Abbreviation: CDVA, corrected distance visual acuity.

five highly hyperopic eyes gained at least one line of vision (22.2\% eyes in the Allegretto 400 series and $23.8 \%$ in the EX500 series [Figure 3]). Vision was stable in eyes treated with each laser platform. Overall, only 24 (11.1\%) of the eyes showed a regression of $\geq+0.75 \mathrm{D}$ at month 6 compared with their goals (Table 4). The results were comparable between the two platforms with $11.7 \%$ for Allegretto 400 series and $9.3 \%$ for EX500 series. No statistical significance was detected between the moderate and high hyperopic eyes $(10.0 \%$ vs $14.0 \%, P>0.05)$. The mean regressions for the 24 eyes showing regression $\geq+0.75 \mathrm{D}$ were $+1.23 \mathrm{D}$ $( \pm 0.79 \mathrm{SD})$ for moderately hyperopic eyes and $+1.63 \mathrm{D}$ $( \pm 1.18 \mathrm{SD})$ for highly hyperopic eyes (Table 5 ).

There were 48 eyes $(22.1 \%)$ that demonstrated a regression of $\geq+0.50 \mathrm{D}$ at month 6 (Table 6) with $23.1 \%$ and $19.3 \%$ for the moderate and the high hyperopic eyes, respectively. Their mean regressions were $+0.81 \mathrm{D}( \pm 0.63 \mathrm{SD})$ and $+1.32 \mathrm{D}( \pm 1.12 \mathrm{SD})$ for the moderate and high hyperopic eyes, respectively (Table 7). There were no significant

Table 4 Number and percent of eyes with regression $\geq 0.75 \mathrm{D}$ from month 6 postoperation compared to the goal

\begin{tabular}{lllll}
\hline $\begin{array}{l}\text { Regression, } \\
\geq \mathbf{0 . 7 5} \text { D }\end{array}$ & $\begin{array}{l}\text { Total } \\
(\mathbf{N}=\mathbf{2} 17 \text { eyes) }\end{array}$ & $\begin{array}{l}\text { Moderate } \\
(\mathbf{n}=\mathbf{1 6 3})\end{array}$ & $\begin{array}{l}\text { High } \\
(\mathbf{n}=\mathbf{5 7})\end{array}$ & P-value $^{\mathbf{a}}$ \\
\hline $\begin{array}{l}\text { Allegretto 400, } \\
\mathbf{n} \text { (\%) }\end{array}$ & 163 & 127 & 36 & 0.6360 \\
Yes & $19(11.66)$ & $14(11.02)$ & $5(13.89)$ & \\
No & $144(88.34)$ & $113(88.98)$ & $31(86.11)$ & \\
EX500, n (\%) & 54 & 36 & 21 & 0.3094 \\
Yes & $5(9.26)$ & $2(6.06)$ & $3(14.29)$ & \\
No & $49(90.74)$ & $31(93.94)$ & $18(85.71)$ & \\
Total, n (\%) & 217 & 160 & 57 & 0.4042 \\
Yes & $24(11.06)$ & $16(10.00)$ & $8(14.04)$ & \\
No & $193(88.94)$ & $144(90.00)$ & $49(85.96)$ & \\
\hline
\end{tabular}

Notes: a $P$-value of chi-square test comparisons in regression rates between patients with moderate and high hyperopia. Regression from goal = SEQ at month $6-$ goal SEQ.

Abbreviations: D, diopters; SEQ, spherical equivalent.
Table 5 Mean regression in patients with month 6 regression $\geq 0.75 \mathrm{D}$ from goal

\begin{tabular}{lllll}
\hline Hyperopia status & $\mathbf{N}$ & Mean \pm SD (D) & Range (D) & $\boldsymbol{P}$-value $^{\mathbf{a}}$ \\
\hline $\begin{array}{l}\text { Allegretto } 400 \\
\text { Moderate }\end{array}$ & 14 & $1.29 \pm 0.82$ & $0.75-3.5$ & 0.1239 \\
High & 5 & $2.10 \pm 1.29$ & $1.0-3.5$ & \\
EX500 & & & & 0.4226 \\
Moderate & 3 & $0.83 \pm 0.14$ & $0.75-1.0$ & \\
High & 2 & $0.75 \pm 0$ & $0.75-0.75$ & \\
Total & & & & 0.3337 \\
Moderate & 16 & $1.23 \pm 0.79$ & $0.75-3.5$ & \\
High & 8 & $1.63 \pm 1.18$ & $0.75-3.5$ & \\
\hline
\end{tabular}

Notes: ${ }^{a} P$-values of two-sided Student's $t$-test for comparisons between patients with moderate and high hyperopia. Moderate $=3.00-4.99 \mathrm{D}$; High $=5.00-6.00 \mathrm{D}$.

Abbreviations: D, diopters; SD, standard deviation.

differences between the mean regressions for the two degrees of hyperopia.

Overall mean SEQ regressions at 6 months compared with goals were 0.10 for eyes with moderate hyperopia and 0.18 for those with high hyperopia (Table 8). Among the 24 eyes showing regression $\geq+0.75 \mathrm{D}$, mean SEQ regression was $+0.21 \mathrm{D}( \pm 0.99 \mathrm{SD})$ for eyes with moderate hyperopia and $+1.06 \mathrm{D}( \pm 1.60 \mathrm{SD})$ for those with high hyperopia (Table 9). Among the 48 eyes demonstrating regression $\geq+0.50 \mathrm{D}$, mean SEQ regression was $-0.26 \mathrm{D}$ $( \pm 0.90 \mathrm{SD})$ for eyes with moderate hyperopia and $+0.77 \mathrm{D}$ ( \pm 1.49 SD) for those with high hyperopia (Table 10).

It is our standard of care to document any abnormal postoperative symptoms in the patient's chart. When deemed necessary, we conduct further clinical evaluations and treatment. For the purposes of this study, we designed a case report form particularly for documenting AEs. There were no AEs reported by the study patients during the 6-month follow-up period.

Table 6 Number and percent of eyes with regression $\geq 0.50 \mathrm{D}$ from month 6 postoperation compared to the goal

\begin{tabular}{lllll}
\hline $\begin{array}{l}\text { Regression } \\
\geq \mathbf{0 . 5 0} \mathbf{D}\end{array}$ & $\begin{array}{l}\text { Total } \\
\mathbf{( N = 2 1 7 )}\end{array}$ & $\begin{array}{l}\text { Moderate } \\
\mathbf{( n = 1 6 3 )}\end{array}$ & $\begin{array}{l}\text { High } \\
\mathbf{( n = 5 7 )}\end{array}$ & P-value $^{\text {a }}$ \\
\hline $\begin{array}{l}\text { Allegretto 400, } \\
\text { n (\%) }\end{array}$ & 163 & 127 & 36 & 0.3745 \\
Yes & $36(22.09)$ & $30(23.62)$ & $6(16.67)$ & \\
No & $127(77.91)$ & $97(76.38)$ & $30(83.33)$ & \\
EX500, n (\%) & 54 & 36 & 21 & 0.8229 \\
Yes & $12(22.22)$ & $7(21.21)$ & $5(23.81)$ & \\
No & $42(77.78)$ & $26(78.79)$ & $16(76.19)$ & \\
Total, n (\%) & 217 & 160 & 57 & 0.5500 \\
Yes & $48(22.12)$ & $37(23.13)$ & $11(19.30)$ & \\
No & $169(77.88)$ & $123(76.88)$ & $46(80.70)$ & \\
\hline
\end{tabular}

Notes: a $P$-value of chi-square test comparisons in regression rates between patients with moderate and high hyperopia. Regression from goal $=$ SEQ at month $6-$ goal SEQ.

Abbreviations: D, diopters; SEQ, spherical equivalent. 
Table 7 Mean regression in patients with month 6 regression $\geq 0.50 \mathrm{D}$ from goal

\begin{tabular}{lllll}
\hline Hyperopia status & $\mathbf{N}$ & Mean \pm SD (D) & Range (D) & $P_{\text {-value }}$ \\
\hline $\begin{array}{l}\text { Allegretto } 400 \\
\text { Moderate }\end{array}$ & 30 & $0.87 \pm 0.68$ & $0.5-3.5$ & 0.1387 \\
High & 6 & $1.83 \pm 1.33$ & $0.5-3.5$ & \\
EX500 & & & & 0.2066 \\
Moderate & 7 & $0.57 \pm 0.12$ & $0.5-0.75$ & \\
High & 5 & $0.70 \pm 0.21$ & $0.5-1.0$ & \\
Total & & & & 0.1786 \\
Moderate & 37 & $0.81 \pm 0.63$ & $0.5-3.5$ & \\
High & $\mathrm{II}$ & $1.32 \pm 1.12$ & $0.5-3.5$ & \\
\hline
\end{tabular}

Notes: ${ }^{a} P$-values of two-sided Student's $t$-test for comparisons between patients with moderate and high hyperopia. Moderate $=3.00-4.99 \mathrm{D}$; High $=5.00-6.00 \mathrm{D}$.

Abbreviations: $\mathrm{D}$, diopters; $\mathrm{SD}$, standard deviation.

\section{Discussion}

There has been historically a strong skepticism of hyperopic corrections because of the high amount of regression and disappointing outcomes in the past. ${ }^{4}$ This prejudice against hyperopic treatments has been significant enough that they only encompass $10 \%$ of most refractive practices. This has also led to other wide-ranging effects on refractive practice over the years, such as the adoption of other treatments to create a prolate cornea such as conductive keratoplasty and corneal inlays. The recognition of the increased stability and decreased regression with technology change has contributed to author MM's practice being 25\%-33\% hyperopic treatment, as well as the easy ability to provide stable monovision treatments in individuals with hyperopic correction. Our longstanding clinical experience has been that very little regression ever occurs after 6 months, with any type of LASIK. This is because epithelial hyperplasia, the major cause of regression, occurs mostly during the first 6 months post-LASIK. ${ }^{5,6}$ Regression can be considered as

Table 8 Mean SEQ regression at month 6 from goal

\begin{tabular}{lllll}
\hline Hyperopia status & $\mathbf{N}$ & Mean \pm SD (D) & Range (D) & $P_{\text {-value }}$ \\
\hline Allegretto 400 & 163 & $0.11 \pm 0.72$ & -1.5 to 3.5 & 0.5876 \\
Moderate & 127 & $0.09 \pm 0.63$ & -1.25 to 3.5 & \\
High & 36 & $0.18 \pm 0.98$ & -1.5 to 3.5 & \\
EX500 & 54 & $0.15 \pm 0.31$ & -0.5 to 1.0 & 0.7008 \\
Moderate & 33 & $0.13 \pm 0.27$ & -0.375 to 0.75 & \\
High & 21 & $0.17 \pm 0.38$ & -0.5 to 1.0 & \\
Total & & & & 0.4947 \\
Moderate & 160 & $0.10 \pm 0.57$ & -1.25 to 3.5 & \\
High & 57 & $0.18 \pm 0.80$ & -1.5 to 3.5 & \\
\hline
\end{tabular}

Notes: ${ }^{2} P$-values of chi-square test for categorical variables and of Student's $t$-test for numeric variables for between-group comparison. Moderate $=3.00-4.99 \mathrm{D}$; High $=5.00-6.00$ D. Per Student's $t$-test, the difference in SEQ regression between the Allegretto 400 and EX500 was not statistically significant $(P=0.5860)$.

Abbreviations: D, diopters; SD, standard deviation; SEQ, spherical equivalent.
Table 9 Mean month 6 SEQ in patients with month 6 regression $\geq 0.75 \mathrm{D}$ from goal

\begin{tabular}{lllll}
\hline Hyperopia status & $\mathbf{N}$ & Mean $\pm \mathbf{S D}$ & Range & $\boldsymbol{P}_{\text {-value }}$ \\
\hline $\begin{array}{l}\text { Allegretto } 400 \\
\text { Moderate }\end{array}$ & 14 & $0.33 \pm 1.00$ & -0.75 to 2.0 & 0.4186 \\
High & 5 & $1.20 \pm 2.1 \mathrm{I}$ & -0.5 to 3.5 & \\
$\begin{array}{l}\text { EX500 } \\
\text { Moderate }\end{array}$ & 2 & $-0.63 \pm 0.18$ & -0.75 to $-0.5 \mathrm{I}$ & \\
High & 3 & $0.83 \pm 0.14$ & 0.75 to 1.0 & \\
$\begin{array}{l}\text { Total } \\
\text { Moderate }\end{array}$ & 16 & $0.21 \pm 0.99$ & -0.75 to 2.0 & 0.1217 \\
High & 8 & $1.06 \pm 1.60$ & -0.5 to 3.5 & \\
\hline
\end{tabular}

Notes: ${ }^{a}$-values of two-sided Student's $t$-test for comparisons between patients with moderate and high hyperopia. Moderate $=3.00-4.99 \mathrm{D} ; \mathrm{High}=5.00-6.00 \mathrm{D}$.

Abbreviations: D, diopters; SD, standard deviation; SEQ, spherical equivalent.

an etiology in other instances also, such as latent hyperopia, which we attempt to avoid in these cases by always using the cyclopeged refraction, or lens changes, which can be determined by no change to the topographic Ks and changes to the refraction. An improper nomogram or an abnormal physiological or structural reaction to the procedure itself would show as an almost immediate residual refraction after the procedure, and we do not count these as regression. It is important here to note the differences between the Allegretto 400 and the EX500 lasers. The obvious is the ablation rate $-400 \mathrm{~Hz}$ for the Allegretto 400 and $500 \mathrm{~Hz}$ for the EX500. The actual wavefront-optimized ablation pattern for hyperopia treatment is the same for both lasers, and with each one a 6.5 optical zone and 9.0 transition zone were used for treatment. The EX500 is $25 \%$ faster than the Allegretto 400, and in removing the larger areas of tissue that a hyperopic treatment requires, this decreases dehydration time. The Allegretto 400 takes about 5 seconds to correct a spherical diopter of hyperopia and the EX500

Table I0 Mean month 6 SEQ in patients with month 6 regression $\geq 0.50 \mathrm{D}$ from goal

\begin{tabular}{lllll}
\hline Hyperopia status & $\mathbf{N}$ & Mean \pm SD & Range & $\boldsymbol{P}_{\text {-value }}$ \\
\hline $\begin{array}{l}\text { Allegretto } 400 \\
\text { Moderate }\end{array}$ & 30 & $-0.21 \pm 0.95$ & -1.0 to 2.0 & 0.2795 \\
High & 6 & $0.83 \pm 2.09$ & -1.0 to 3.5 & \\
EX500 & & & & 0.0033 \\
Moderate & 7 & $-0.46 \pm 0.68$ & -1.0 to 0.5 & \\
High & 5 & $0.70 \pm 0.21$ & 0.5 to 1.0 & \\
Total & & & & 0.0486 \\
Moderate & 37 & $-0.26 \pm 0.90$ & -1.0 to 2.0 & \\
High & $\mathrm{II}$ & $0.77 \pm 1.49$ & -1.0 to 3.5 & \\
\hline
\end{tabular}

Notes: ${ }^{a}$-values of two-sided Student's $t$-test for comparisons between patients with moderate and high hyperopia. Moderate $=3.00-4.99 \mathrm{D}$; High $=5.00-6.00 \mathrm{D}$. Abbreviations: D, diopters; SD, standard deviation; SEQ, spherical equivalent. 
takes about 3.75 seconds. This is in comparison to a VISX S4, which takes 20 seconds per diopter.

Also critically important is the tracking system. The Allegretto 400 uses a $400 \mathrm{~Hz}$ tracker, while the EX500 uses a $1,000 \mathrm{~Hz}$ tracker. The system is limited by the fact that the 500 laser head can only function at $500 \mathrm{~Hz}$, so the $1,000 \mathrm{~Hz}$ tracker essentially oversamples and allows for immediate reaction by the laser head. This is important because the fastest eye movement, a saccade, takes 0.2 seconds, which translates into $500 \mathrm{~Hz}$. This makes the EX500 tracker the first we have had in the USA that can keep up with the fastest eye movement. For longer ablation times that are mainly removing the larger areas of tissue peripherally needed in hyperopic correction, this faster tracker likely makes a significant difference as a more discrete ablation pattern will be created, decreasing the chances of a more ragged profile, which could encourage epithelial hyperplasia and, therefore, regression.

These factors have led to ablations with larger optical zones that are more resistant to epithelial hyperplasia and resulting regression. Interestingly, FDA approval of higher amounts of correction on these lasers did not lead to a widespread acceptance of treating above $3 \mathrm{D}$ of hyperopia, even with WaveLight surgeons in the USA still actively recommending that no more than $4 \mathrm{D}$ of hyperopia be treated.

Finally, we found that the other major difference between the Allegretto 400 and the EX500 was nomogram use. Although we used IBRA for the EX500 and Datalink for the Allegretto 400, we found that from the initial use of the EX500 it required no nomogram adjustment for hyperopia treatment, and the refraction was simply entered. This stayed this way through the duration of the retrospective study time period, and is that way as of this writing. The Allegretto 400 required a nomogram adjustment, and both machines were in the same operating room, with the same conditions, and procedures were performed by the same surgeon.

The authors noted in their clinical experience, from 2010 onwards, that the Allegretto 400 hyperopic corrections were more accurate and stable than with prior lasers used. As higher and higher treatments were performed, the results were still quite good, and upon switching to the EX500 there was a clinical sense that this laser was even more accurate. Over time author MM became aware that many refractive surgeons still had a bias toward hyperopic correction. Upon speaking to physicians in the community, as well as noting online forum recommendations, it became clear to the authors that past perception of hyperopic regression and instability had outweighed trust in the change in technology and even the FDA approvals. Thus, this retrospective study was undertaken to quantify this clinical experience into actual statistical outcomes.

We classified the results into regression $\geq+0.50$ and $+0.75 \mathrm{D}$. The data are presented this way as $+0.50 \mathrm{D}$ has been a mainstay of measurement in most past studies, and this level of regression or inaccuracy is acceptable to most patients with hyperopic treatment. Patients with a result $+0.75 \mathrm{D}$ from the goal virtually always notice and often opt for retreatment if possible, and we chose to call this measure "significant regression." Looking at this category in Table 4 reveals that only $11.66 \%$ of Allegretto 400 cases had significant regression, and only $9.26 \%$ of the EX500 cases did; a significantly lower number than most refractive surgeons would expect. Where the Allegretto 400 and EX500 differ markedly is the range of regression, which is much tighter and lower on the EX500 ( +0.75 to $+1.0 \mathrm{D}$ vs +0.75 to $+3.5 \mathrm{D})$. In both the moderate and high hyperopia groups the Allegretto 400 had a range as high as $+3.5 \mathrm{D}$ of regression, while only $+1.0 \mathrm{D}$ for the EX500. High levels of regression did not occur often even in the Allegretto 400 group, with the average amount of regression on the Allegretto 400 at 6 months postoperation only being $+0.11 \mathrm{D}$ and on the EX500 only being $+0.15 \mathrm{D}$.

This is also further borne out by the fact that the mean regression in those eyes with moderate hyperopia that had "significant regression" on the Allegretto 400 was $+1.29 \mathrm{D}$, and on the EX500 was +0.83 D. Furthermore, no eyes treated with the EX500 lost CDVA, while two eyes treated with the Allegretto 400 lost a line of CDVA.

Overall, this study found comparable efficacy and safety of treatment with the WaveLight Allegretto $400 \mathrm{~Hz}$ and EX500 $500 \mathrm{~Hz}$ excimer laser systems in patients with moderate-to-high hyperopia. In general, there was a tendency for a slight gain in lines of vision for eyes treated with both the Allegretto 400 and the EX500 laser. Both excimer laser systems achieved very small differences between the month 6 SEQs and the goal SEQs (mean $\leq+0.2 \mathrm{D}$ ), demonstrating excellent reproducibility, predictability, and postoperative vision stability.

There is some existing evidence to support the safety and efficacy of LASIK in eyes with moderate-to-high hyperopia. A small case series compared differences in induced aberrations and visual acuity after wavefront-optimized LASIK and aspheric-customized LASIK using the Allegretto 400 system for the treatment of moderate hyperopia $(+3.82 \pm 0.63 \mathrm{D}$; range +2.75 to $+5.13 \mathrm{D} ; \mathrm{n}=40$ eyes). ${ }^{7}$ A standard procedure was utilized in the wavefront-optimized LASIK group $(n=24)$, while a postoperative Q-factor equal to zero was used 
in the aspheric-customized LASIK group $(n=16)$. The results of this case series suggest that using an aspheric-customized ablation profile with a target Q-factor equal to 0 in moderate hyperopic eyes undergoing LASIK was statistically compatible with a diminishing induced spherical aberration without having an adverse effect on the safety of the procedure. The current study, in a larger group of patients confirmed the safety and visual stability using the Allegretto 400 system for the treatment of moderate-to-severe hyperopia.

Kanellopoulos ${ }^{8}$ evaluated the safety and efficacy of topography-guided ablation using the WaveLight $400 \mathrm{~Hz}$ excimer laser system in 208 consecutive LASIK cases with

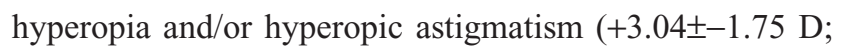
range $+0.75-+7.25 \mathrm{D})$. Flaps were created either with the FS200 (Alcon, Fort Worth, TX, USA) or the Intralase FS60 (AMO, Irvine, CA, USA) femtosecond lasers. UDVA improved from 5.5/10 to 9.2/10. At 24 (range 8-37) months, $75.5 \%$ of the eyes were within $\pm 0.50 \mathrm{D}$ and $94.4 \%$ were within $\pm 1.00 \mathrm{D}$ of the refractive goal. Approximately $46.6 \%$ of cases gained at least one line of visual acuity postoperatively. No significant complications were observed. The results are noteworthy for the amount of refractive error correction, stability of vision, and for the improvement of both UDVA and CDVA achieved. The current study also achieved favorable patient outcomes for these same visual parameters. At month $6,77.9 \%$ of eyes were within $+0.50 \mathrm{D}$ of goal while $88.9 \%$ of eyes were within +0.75 D of goal.

Durrie et $\mathrm{al}^{9}$ conducted a prospective, randomized, singlecenter clinical trial in 51 consecutive eyes to compare visual outcomes and induced spherical aberration after conventional (LADAR4000 excimer laser [Alcon, Fort Worth, TX, USA]; n=25) and wavefront-optimized LASIK (WaveLight Allegretto excimer laser; $n=26$ ) for the treatment of low-tomoderate hyperopia. On postoperative day 1, 20\% of eyes treated with a conventional profile had UDVA of 20/20 or better compared to $65 \%$ of eyes receiving wavefrontoptimized treatment $(P=0.0011)$. Six months after surgery, $72 \%$ and $84 \%$ of the conventional and wavefront-optimized treatment groups, respectively $(P=0.3254)$, achieved UDVA that was $20 / 20$ or better and the manifest refraction SEQ was $-0.21 \pm 0.47 \mathrm{D}$ and $0.16 \pm 0.27 \mathrm{D}$, respectively. Both systems performed well at predictably and safely correcting low-to-moderate hyperopia. In comparison, at 6 months, the current study found the mean UDVA of 35.14 \pm 23.12 and a mean SEQ of $-0.67 \pm 0.96 \mathrm{D}$.

Another study, published about 10 years ago, evaluated the safety and efficacy of the Allegretto Wave excimer laser system in LASIK in 120 consecutive LASIK cases for hyperopia with or without astigmatism. ${ }^{10}$ Patients were subdivided into three groups according to their refractive sphere and cylinder: a low hyperopia group, with up to $+3.00 \mathrm{D}$ sphere and astigmatism $\leq+1.00 \mathrm{D}(\mathrm{n}=52)$; a moderate hyperopia group with $+3.25-+5.00 \mathrm{D}$ sphere and astigmatism of $\leq+1.00 \mathrm{D}(\mathrm{n}=45)$; and a high hyperopia/toric group with sphere $\geq+5.25$ D or cylinder $\geq+1.25$ D $(n=23)$. Patients were followed up to 12 months postoperatively. For eyes in the low hyperopia group, $92 \%$ were within $\pm 0.50 \mathrm{D}$ of the refractive goal. For the moderate sphere group and the high hyperopia/toric group, $79 \%$ and $71 \%$ of eyes, respectively, were within $\pm 0.50 \mathrm{D}$ of their refractive goal. However, an increase in higher-order aberrations was noted in the high hyperopia/toric group. No significant changes in higher-order aberrations were noted in the low and moderate hyperopia groups. These results are comparable to those from the current study in moderate and high hyperopes where $77.9 \%$ of eyes were within $+0.50 \mathrm{D}$ of goal at month 6 postoperation.

Excimer laser systems have recently been developed with innovative features, such as high repetition rates (400 and $500 \mathrm{~Hz}$ ) and customized ablation profiles., ${ }^{1,6,11-14}$ These enhanced features have improved the effectiveness and safety of LASIK surgery, thus making treatment possible for a broad range of patients, including those with moderate-to-relatively high hyperopia. These lasers are approved for up to $+6.0 \mathrm{D}$ of hyperopic treatment although some more conservative refractive surgeons need additional clinical evidence in order to be confident in performing laser correction on eyes with $\geq+3.0 \mathrm{D}$ of hyperopia. It has been shown that higher repetition rates may provide better ablation quality vs slower systems. ${ }^{15}$ This improvement in ablation quality is thought to be due to a decrease in stromal dehydration, flap shrinkage, fixation fatigue, and sensitivity to eye movements. ${ }^{1,2,16}$

It is necessary at this point to note a tendency of the EX500 laser, and to a lesser extent the Allegretto 400 laser, to track patients and allow ablation even if the eye is somewhat tilted superiorly or inferiorly. This results in eccentric ablations, and in poor visual outcomes. With hyperopic ablations this will result in higher amounts of regression in our experience, and the situation worsens if an enhancement is done and lines up differently than with the original correction. This tendency has been noted after the original study and manuscript were finished, and it was deemed a significant enough precaution to add to the manuscript during final revisions. The best way to avoid this from occurring is to turn off the center light during ablation, as this makes it easier for the patient to focus on the flashing green fixation light, and the surgeon must then ensure that the fixation light is centered in the pupil and the patient is not looking slightly up or down and fixating the light in peripheral retina. We as 
surgeons simply cannot trust the trackers when it comes to tilt, and must verify ourselves.

This study is limited by its retrospective single-center design. These findings should be verified in a larger multicenter, randomized, prospective clinical trial with longer follow-up. Patient symptoms (such as difficulty driving at night) after surgery were not assessed. Qualitative analyses could be done as a follow-up study, but our anecdotal and clinical experience was that patients were at least as satisfied with their vision as wavefront-optimized myopic/myopic astigmatism patients. Our experience demonstrated patients with fast visual rehabilitation, rapid stabilization of vision, and similar ratios of nighttime vision issues as myopic patients (ie, fairly low).

It was expected that the two devices would produce comparable clinical results because EX500 is basically an upgrade of Allegretto 400 (this expectation was proven again in this study). Therefore, it was not our intention to compare head-to-head the two platforms. Regardless, we reported results individually for each platform when deemed clinically relevant, or for the benefit of our audience, and no statistically significant difference was detected between the two platforms for the results studied.

In conclusion, both the 400 and $500 \mathrm{~Hz}$ excimer laser systems were safe and effective in the treatment of moderateto-high hyperopia with LASIK. Both systems achieved small differences between the month 6 SEQs and the goal SEQs (means $\leq+0.2 \mathrm{D}$ ), demonstrating excellent reproducibility, predictability, and postoperative vision stability. The overall rate of regression over the 6-month follow-up period was high but the amount of regression was relatively small with both systems with the majority of eyes having $+0.50 \mathrm{D}$ or less.

\section{Acknowledgments}

The authors would like to acknowledge Julie Crider, PhD, for medical writing contributions; Jenny Song, MD, MS, for the statistical analysis; Kenneth Yam, BS, for concept, data collection, and scientific research; Jiten Mehta, BS, for concept, data collection, and scientific research.

Drs. Motwani and Pei received an unrestricted grant from Alcon for this study.

Clinical Ophthalmology

\section{Publish your work in this journal}

Clinical Ophthalmology is an international, peer-reviewed journal covering all subspecialties within ophthalmology. Key topics include: Optometry; Visual science; Pharmacology and drug therapy in eye diseases; Basic Sciences; Primary and Secondary eye care; Patient Safety and Quality of Care Improvements. This journal is indexed on

\section{Disclosure}

The authors report no conflicts of interest in this work.

\section{References}

1. Kanellopoulos AJ, Asimellis G. Long-term bladeless LASIK outcomes with the FS200 Femtosecond and EX500 Excimer Laser workstation: the Refractive Suite. Clin Ophthalmol. 2013;7:261-269.

2. Cummings AB, Corkin RH. Comparing 3 WaveLight Excimer lasers of different speeds and generations, presented at the European Society of Cataract and Refractive Surgery (ESCRS), Paris, September 2010.

3. WaveLight ${ }^{\circledR}$ Excimer Laser Systems (Product Information). Fort Worth, TX. Alcon Laboratories, Inc.; 2016.

4. Lipner M. Exploring hyperopic LASIK. Eyeworld. May 2002. Available from: http://www.eyeworld.org/printarticle.php?id=1348. Accessed January 11, 2016.

5. Kezirian GM, Moore CR, Stonecipher KG; SurgiVision Consultants Inc WaveLight Investigator Group. Four-year postoperative results of the US ALLEGRETTO WAVE clinical trial for the treatment of hyperopia. J Refract Surg. 2008;24(4):S431-S438.

6. Frings A, Richard G, Steinberg J, Druchkiv V, Linke SJ, Katz T. LASIK and PRK in hyperopic astigmatic eyes: is early retreatment advisable? Clin Ophthalmol. 2016;10:565-570.

7. Amigo A, Bonaque-Gonzalez S, Guerras-Valera E. Control of induced spherical aberration in moderate hyperopic LASIK by customizing corneal asphericity. J Refract Surg. 2015;31(12):802-806.

8. Kanellopoulos AJ. Topography-guided hyperopic and hyperopic astigmatism femtosecond laser-assisted LASIK: long-term experience with the $400 \mathrm{~Hz}$ eye-Q excimer platform. Clin Ophthalmol. 2012; 6:895-901.

9. Durrie DS, Smith RT, Waring GO 4th, Stahl JE, Schwendeman FJ. Comparing conventional and wavefront-optimized LASIK for the treatment of hyperopia. J Refract Surg. 2010;26(5):356-363.

10. Kanellopoulos AJ, Conway J, Pe LH. LASIK for hyperopia with the WaveLight excimer laser. J Refract Surg. 2006;22(1):43-47.

11. Mrochen M, Schelling U, Wuellner C, Donitzky C. Influence of spatial and temporal spot distribution on the ocular surface quality and maximum ablation depth after photoablation with a $1050 \mathrm{~Hz}$ excimer laser system. J Cataract Refract Surg. 2009;35(2):363-373.

12. de Ortueta D, Magnago T, Triefenbach N, Arba Mosquera S, Sauer U, Brunsmann U. In vivo measurements of thermal load during ablation in high-speed laser corneal refractive surgery. J Refract Surg. 2012; 28(1):53-58.

13. Aslanides IM, Kolli S, Padroni S, Arba Mosquera S. Stability of therapeutic retreatment of corneal wavefront customized ablation with the SCHWIND CAM: 4-year data. J Refract Surg. 2012;28(5):347-352.

14. Smadja D, Reggiani-Mello G, Santhiago MR, Krueger RR. Wavefront ablation profiles in refractive surgery: description, results, and limitations. J Refract Surg. 2012;28(3):224-232.

15. Winkler von Mohrenfels C, Khoramnia R, Lohmann CP. Comparison of different excimer laser ablation frequencies $(50,200$, and $500 \mathrm{~Hz})$. Graefes Arch Clin Exp Ophthalmol. 2009;247(11):1539-1545.

16. Matsuura T, Ikeda H, Idota N, Motokawa R, Hara Y, Annaka M. Anisotropic swelling behavior of the cornea. J Phys Chem B. 2009;113(51): 16314-16322.

PubMed Central and CAS, and is the official journal of The Society of Clinical Ophthalmology (SCO). The manuscript management system is completely online and includes a very quick and fair peer-review system, which is all easy to use. Visit http://www.dovepress.com/ testimonials.php to read real quotes from published authors. 